\title{
UV-Cured Biodegradable Methacrylated Starch-Based Coatings
}

\author{
Camilla Noè $^{1} \mathbb{D}$, Chiara Tonda-Turo ${ }^{2}\left(\mathbb{D}\right.$, Irene Carmagnola ${ }^{2} \mathbb{D}$, Minna Hakkarainen ${ }^{3}$ (D) \\ and Marco Sangermano ${ }^{1, *(\mathbb{D})}$
}

1 Politecnico di Torino, Dipartimento di Scienza Applicata e Tecnologia, C.so Duca Degli Abruzzi 24, 10129 Torino, Italy; camilla.noe@polito.it

2 Politecnico di Torino, Dipartimento di Ingegneria Meccanica e Aerospaziale, C.so Duca Degli Abruzzi 24, 10129 Torino, Italy; chiara.tondaturo@polito.it (C.T.-T.); irene.carmagnola@polito.it (I.C.)

3 Department of Fibre and Polymer Technology, KTH Royal Institute of Technology, 10044 Stockholm, Sweden; minna@kth.se

* Correspondence: marco.sangermano@polito.it

\section{check for}

updates

Citation: Noè, C.; Tonda-Turo, C.; Carmagnola, I.; Hakkarainen, M.; Sangermano, M. UV-Cured Biodegradable Methacrylated Starch-Based Coatings. Coatings 2021, 11, 127. https://doi.org/10.3390/ coatings11020127

Received: 22 December 2020

Accepted: 20 January 2021

Published: 23 January 2021

Publisher's Note: MDPI stays neutral with regard to jurisdictional claims in published maps and institutional affiliations.

Copyright: (c) 2021 by the authors. Licensee MDPI, Basel, Switzerland. This article is an open access article distributed under the terms and conditions of the Creative Commons Attribution (CC BY) license (https:// creativecommons.org/licenses/by/ $4.0 /)$.

\begin{abstract}
Promising UV-curable starch-based coatings were fabricated by utilizing methacrylated starch. The aqueous methacrylated starch solution was cast on a glass substrate, and UV-cured after drying. The efficiency of UV-curing process was monitored with gel percentage measurements. The thermal and mechanical properties of the fabricated UV-cured coatings were investigated through differential scanning calorimetry and tensile test and compared with the starch-based uncured casted coatings. A complete characterization of the surface properties was performed by means of pencil hardness, adhesion, solvent resistance, and surface tension measurements. The cross-linking by UVcuring significantly enhanced the mechanical and surface properties of the coating. The effect of UVcuring on the biodegradability of the coating was evaluated by following the enzymatic degradation by $\alpha$-amylase by determining the amount of glucose and maltose released from the coatings. UVcured methacrylated starch based coating with promising material and surface properties and retained biodegradation potential was demonstrated.
\end{abstract}

Keywords: starch; biodegradable coatings; UV-curing

\section{Introduction}

Nowadays, we witness a steady rise in introduction of new bio-renewable resources as alternatives for petroleum-derived polymeric materials due to increased environmental concerns and depletion of petroleum feedstocks.

Among bio-renewable monomers, a large variety of molecules containing rigid aromatic backbone have been explored as polymer precursor such as polysaccharides [1], lignin [2], vanillin [3], eugenol [4], and cinnamic acid [5,6]. Thermosetting polymers obtained from those monomers usually possess high mechanical properties, due to the presence of the rigid aromatic backbone structure. It is important to stress that the term "biobased" denotes a product derived from renewable resources but does not imply biodegradability [7]. In fact, the research interest on biobased materials largely focus on increasing the durability and performances, rather than in the biodegradability.

Another attractive class of biobased materials is vegetable oils (VO). In fact, VO are constituted by triglycerides and possess several highly reactive sites. Moreover, they are potentially biodegradable in soil since their glycerol ester bond can be hydrolytically cleaved [8].

While vegetable oils have been widely utilized in non-edible coating applications [9-13], carbohydrate polymers were less explored because of their short shelf time and mechanical weakness. Polycarbohydrates can be obtained from a variety of sources like cellulose (carboxymethylcellulose, methylcellulose, etc.), starch (carboxymethylstarch, hydroxypropyl starch), seaweed extracts (alginate, agar, etc.), exoskeleton of crustaceans and insects (chitin, chitosan, etc.), and different types of microbial gums (xanthan, pullulan, etc.) [14]. Coatings made of polysaccharides are usually colourless and efficient oxygen blockers. Thanks to 
those qualities, they are extensively used as barrier for food protection in the packaging industry [15]. Among carbohydrates, starch is abundant in plants, biodegradable, and very cheap [16]. It is composed of two different polymers consisting of $\alpha(1-4)$ linked D-glucose units: amylose and amylopectin. Amylose is linear, while amylopectin is highly branched with $5 \%-6 \%$ of $\alpha(1-6)$ linkages. The ratio of those polymers varies based on the starch sources. For example, the amylose percentage in tapioca is $17 \%$, in corn $25 \%-28 \%$ and in high amylose maize starch $70 \%$. Starch is also non-toxic, polyfunctional, and has high chemical reactivity. However, the hydrophilicity and tendency of the starch granules to swell and rupture, has limited the industrial use of unmodified starch, especially in material applications [17]. Two strategies can be applied to overcome these drawbacks: (1) starch can be blended with other biobased materials [18-21]; (2) starch can be chemically modified, either by grafting or cross-linking. With well-designed modification both moisture resistance and mechanical properties of the material can be improved [22,23].

Chemically modified starch, therefore, could be an important starting precursor for the production of bio-based coatings. To induce network formation, different cross-linking agents have been proposed [24-27] exploiting thermal curing process.

Compared to conventional thermal-curing, UV-curing technology shows important advantages in-line with principals of green chemistry including very fast curing reaction, low energy consumption and solventless process [28-30].

In previous papers, light processable starch precursors were investigated for hydrogel preparation [31,32]. A few radiative processes involving gamma or electron beam irradiation were also proposed to induce crosslinking of starch [33-38].

The purpose of this study was to exploit and investigate methacrylated starch as a potential precursor for the production of UV-curable film coatings. The UV-curing process of the water-casted films is described, and the mechanical and surface properties of the obtained networks are fully characterized. Finally, the effect of UV-curing on the biodegradability was investigated by subjecting the uncured and cured coatings to $\alpha$-amylase enzyme. The degradation process was monitored by analysing the amount of glucose and amylose released to the natant medium.

\section{Materials and Methods}

\subsection{Materials}

High-amylose Hylon VII maize starch (70\% amylose) was obtained from Ingredion, Goole, UK. Methacrylic anhydride (MA), triethylamine (TEA) (>99\%), dimethyl sulfoxide (DMSO) (ACS reagent P99.9\%), ethanol absolute and bis(acyl)phosphane oxi lithium phenyl-2,4,6-trimethylbenzoylphosphinate (LAP) were purchased from Sigma Aldrich (Milan, Italy).

\subsection{Synthesis of Methacrylated Starch}

Methacrylated starch (MS) was synthetized as previously reported [32]. Briefly, $6 \mathrm{~g}$ of high amylose maize starch was solubilized in $200 \mathrm{~mL}$ of DMSO at $70^{\circ} \mathrm{C}$. After $30 \mathrm{~min}$, the solution was let cool down at room temperature. Subsequently, methacrylic anhydride and triethylamine were added dropwise (molar ratio AGU (Anydrous Glucose Unit):MA:TEA of 1:2:0.04). The solution was then left to react for $18 \mathrm{~h}$. The final product was precipitated in ethanol, dissolved in de-ionized water, and again precipitated in ethanol. After repeating this procedure two more times, the final aqueous solution was lyophilized. The methacrylation reaction was evaluated and confirmed by proton and carbon nuclear magnetic resonance $\left({ }^{1} \mathrm{H}-\mathrm{NMR},{ }^{13} \mathrm{C}-\mathrm{NMR}\right)$, and fourier transform infrared (FTIR) spectroscopy (The characterization of methacrylated starch was reported in reference [32]).

\subsection{Casting and Photocuring of Methacrylated Starch Coating}

Methacrylated starch was suspended in de-ionized water (10 wt.\% MS). After the complete solubilization, LAP as a photoinitiator in the content of $1 \mathrm{wt} . \%$ with respect to the starch weight was added. Then, the solution was immediately casted on a glass substrate. 
The solution was completely dried in air and subsequently irradiated with a DYMAX UV static lamp (125 mW/ $\mathrm{cm}^{2}$ ) (Dymax, Torrington, USA) to fabricate the methacrylated starch cured film (MSC, $100 \mu \mathrm{m})$.

\subsection{Characterization}

2.4.1. Attenuated Total Reflectance-Fourier Transform Infrared Spectroscopy (ATR-FTIR)

The FTIR spectra of starch and methacrylated starch were recorded by Perkin Elmer Spectrum 2000 FTIR spectrometer (Perkin Elmer, Norwalk, CT, USA) equipped with a single reflection attenuated total reflectance (ATR) accessory. For each sample, 16 scans were recorded with $4 \mathrm{~cm}^{-1}$ resolution.

\subsubsection{Gel Content}

The gel content percentage ( $G \%$ ) of the cured films was determined by measuring the weight loss after $24 \mathrm{~h}$ extraction with hot water at $60^{\circ} \mathrm{C}$. G\% was calculated according to Equation (1):

$$
G \%=\frac{W_{i}}{W_{0}} \times 100 \%
$$

where $W_{i}$ is the weight of the dry film after the treatment with water and $W_{0}$ is the weight of the dry sample before the treatment.

\subsubsection{Differential Scanning Calorimetry (DSC)}

Differential scanning calorimetric analysis was carried out on a Mettler Toledo DSC instrument (Mettler-Toledo, Stockholm, Sweden) at a heating rate of $10^{\circ} \mathrm{C} / \mathrm{min}$ using a nitrogen atmosphere. Samples (10-12 mg) were sealed in a $100 \mu \mathrm{L}$ aluminium pan with pierced lids.

\subsubsection{Tensile Test}

Tensile tests were performed on dry rectangular specimens $(1 \mathrm{~cm} \times 10 \mathrm{~cm})$ with $600 \mu \mathrm{m}$ thickness using MTS QTest ${ }^{\mathrm{TM}} / 10$ Elite controller (MTS Systems Corporation, Edan Prairie, Minnesota, USA) using TestWorks ${ }^{\circledR} 4$ software (Edan Prairie, Minnesota, USA). The traction force was applied along the length of the samples at a constant cross-head displacement rate of $2 \mathrm{~mm} / \mathrm{min}$. The Young's modulus $(E)$ of each sample was calculated from the slope of the initial linear portion of the stress-strain curve. The ultimate tensile strength and elongation at break were calculated as the maximum stress value in the stress-strain curve. Five samples for each film were tested.

\subsubsection{Pencil Hardness}

The pencil hardness test was performed using pencils of different grades starting from the $6 \mathrm{H}$ and continuing down the scale, testing with softer and softer pencils according to ASTM D 3363-74 [39]. The pencils were maintained at $45^{\circ}$ and pushed for at least $6 \mathrm{~mm}$ with uniform pressure and speed onto the coating surface. The hardness of the coating was taken as that of the hardest pencil, which caused a cut less than $3 \mathrm{~mm}$ long out of the $6 \mathrm{~mm}$ test push on the surface of the coating.

\subsubsection{Adhesion Measurement}

The coating adhesion measurements were performed according to the ASTM D3359-B [40]. The surface of each coating was scratched both vertically and horizontally with a blade holding 6 teeth, separated from each other by a $2 \mathrm{~mm}$ distance. A strip of adhesive tape was then applied and subsequently pulled away with a $180^{\circ}$ angle. The percentage of squares where the coating was still intact was reported. 


\subsubsection{Solvent Rub Resistance test}

The coating chemical resistance was evaluated by methyl ethyl ketone (MEK) double rub test according to the ASTM D5402 [41]. Double rubs were performed until the substrate was exposed, or for a maximum of 200 rubs.

\subsubsection{Contact Angle}

Contact angle measurements were performed with a Kruss DSA10 instrument (Hamburg, Germany), equipped with a video camera. Analyses were conducted using the sessile drop technique at room temperature. Ten measurements were performed on each sample. The surface free energy $(\gamma)$ was determined based on Owens-Wendt-Rabel-Kaelble (WORK) method. [42] The measuring liquids were double distilled water $(\gamma=72.8 \mathrm{mN} / \mathrm{m})$ and hexadecane $(\gamma=27.6 \mathrm{mN} / \mathrm{m})$.

\subsubsection{Enzymatic Degradation}

The enzymatic degradation test was carried out by using $\alpha$-amylase from bacillus licheniformis. Pre-weighted samples $(4 \mathrm{~mm} \times 6 \mathrm{~mm} \times 0.4 \mathrm{~mm})$ were incubated in phosphate buffer saline (PBS) solution containing $0.6 \mathrm{mg} / \mathrm{mL}$ of the enzyme at $37^{\circ} \mathrm{C}$ for 2 weeks. At different time points (2, 5, 7 and 14 days), supernatants were collected. The enzymatic degradation of MS and MSC was quantified by measuring the amount of maltose and glucose using The Maltose and Glucose Assay kit provided by Sigma Aldrich. Briefly, $50 \mu \mathrm{L}$ of supernatants were mixed with $50 \mu \mathrm{L}$ of master reaction mix containing a glucose probe, which quantifies the amount of glucose generating a colorimetric product $(570 \mathrm{~nm})$. To measure the amount of maltose, an additional $50 \mu \mathrm{L}$ of supernatants were mixed with $50 \mu \mathrm{L}$ of master reaction mix containing a glucose probe and a-D-Glucosidase enzyme able to degrade maltose into two glucose units. The absorbance at $570 \mathrm{~nm}$ was detected using a multimode plate reader (SYNERGY, BioTeK, Wimooski, VT, USA). Three samples for each condition were used and experiments were performed three times. GraphPad Prism ${ }^{\circledR}$ software (Graph Pad Prism 8.3.0) was used for one or two way analysis of variance (ANOVA). Values * $p<0.05$ were considered statistically significant. To monitor the $\alpha$ amylase activity over time, a control solution containing only the enzyme in PBS was prepared and stored at $37^{\circ} \mathrm{C}$.

\section{Results and Discussion}

Starch was modified with methacrylic anhydride (Scheme 1, as already reported in a previous paper from our group [32]) in order to exploit the methacrylic functional groups in UV-curing process. Fully transparent tack-free crosslinked coatings were achieved, and thermal, mechanical, and surface properties of the crosslinked networks were evaluated.

\subsection{Confirmation of Starch Methacrylation and Photocuring Process}

The FTIR spectra of starch (S) and methacrylate starch (MS) are reported in Figure 1a. The starch spectrum shows the characteristic functional groups of starch. In the fingerprint region, the peaks at 760 and $859 \mathrm{~cm}^{-1}$ represent the $C-C$ stretching vibration and $C(1)-H$, $\mathrm{CH}_{2}$ deformation, respectively. The peaks at 929 , and $995 \mathrm{~cm}^{-1}$ represent the skeletal vibration of $\mathrm{C}-\mathrm{O}-\mathrm{C} \alpha-1-4$ glycosidic linkage, while the peak at $1076 \mathrm{~cm}^{-1}$ is the $\mathrm{C}-\mathrm{H}$ bending vibration. The peak at $1149 \mathrm{~cm}^{-1}$ corresponds to the $\mathrm{C}-\mathrm{O}-\mathrm{C}$ stretching vibrations of the cyclic ether group. The peaks at 1300 and $1360 \mathrm{~cm}^{-1}$ are attributed to the $-\mathrm{CH}_{2}$ - and $\mathrm{C}-\mathrm{O}$ vibrations. The band at $1638 \mathrm{~cm}^{-1}$ corresponds to the absorbed water in starch. The peak at $2925 \mathrm{~cm}^{-1}$ is the $-\mathrm{CH}_{2}-$ stretching vibration, while the broad peak at $3270 \mathrm{~cm}^{-1}$ is assigned to the $-\mathrm{OH}$ vibration $[43,44]$. In the MS spectrum, it is possible to observe the appearance of new peaks that confirm the success of the methacrylation reaction. The peaks at 1300 and $1710 \mathrm{~cm}^{-1}$ represent the $\mathrm{C}-\mathrm{O}$ and $\mathrm{C}=\mathrm{O}$ stretching vibrations, respectively. It is also possible to observe an enhancement and sharpness of the $1638 \mathrm{~cm}^{-1}$ peak intensity, which can be due to the $\mathrm{C}=\mathrm{CH}_{2}$ out of plane bending vibrations $[32,45]$. 


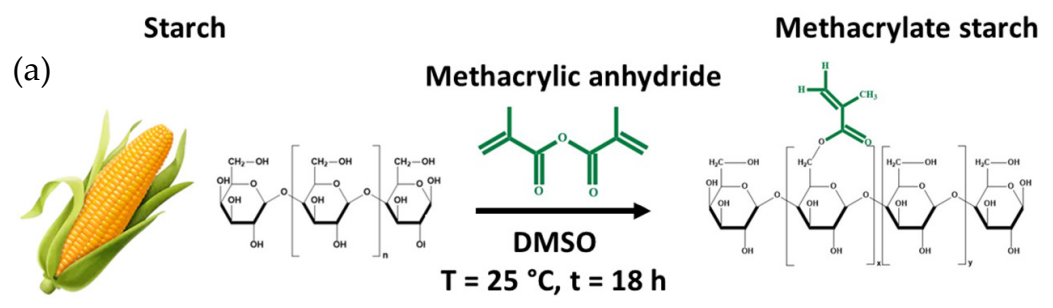

(b) Uncrosslinked metacrylate starch

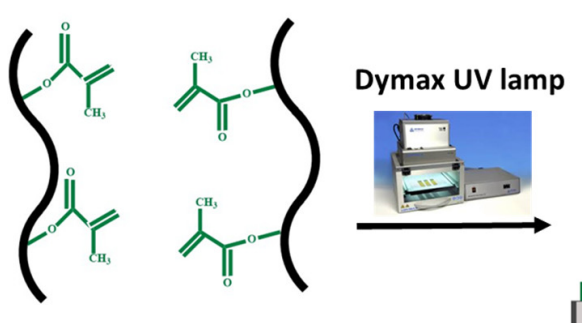

Crosslinked

methacrylate starch

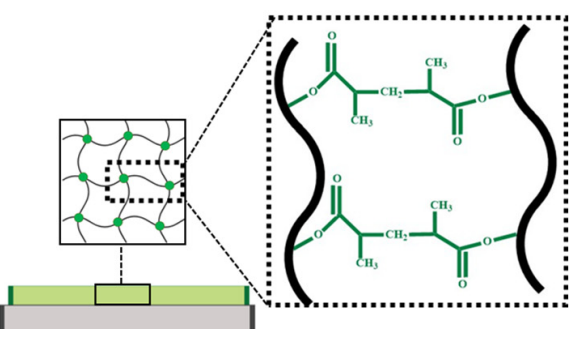

Scheme 1. (a) Methacrylation reaction; (b) schematic representation of the photo-crosslinking reaction.

The MS was dissolved in water and films were achieved by solvent-casting. Photocrosslinking reaction was performed, after water evaporation, by UV-irradiation under inert atmosphere.

Since the methacrylic peak signal at $1638 \mathrm{~cm}^{-1}$ is overlapped with the peak of tightly bound water (already present in the native starch), FTIR analysis to follow the UV-Curing process kinetics was not possible. For this reason, the efficiency of curing was evaluated by measuring the insoluble content $(\mathrm{Gel} \%)$ at different irradiation time. As shown in Figure $1 \mathrm{~b}$, the increase of irradiation time leads to an increment of the gel fraction, thus confirming the network formation. The equilibrium Gel\% value (83\%) was reached after $15 \mathrm{~min}$. However, it can be stressed that after $10 \mathrm{~min}$, the insoluble fraction is already above $78 \%$. The obtained Gel\% values are comparable with those reported in literature for the cross-linked starch with sodium benzoate (85\%) [34]. Nevertheless, previous works used DMSO as a solvent to estimate the film insoluble fraction. However, DMSO requires several washes to be completely removed. In this work, to avoid those passages, water was used as an extraction solvent in which MS was originally soluble.
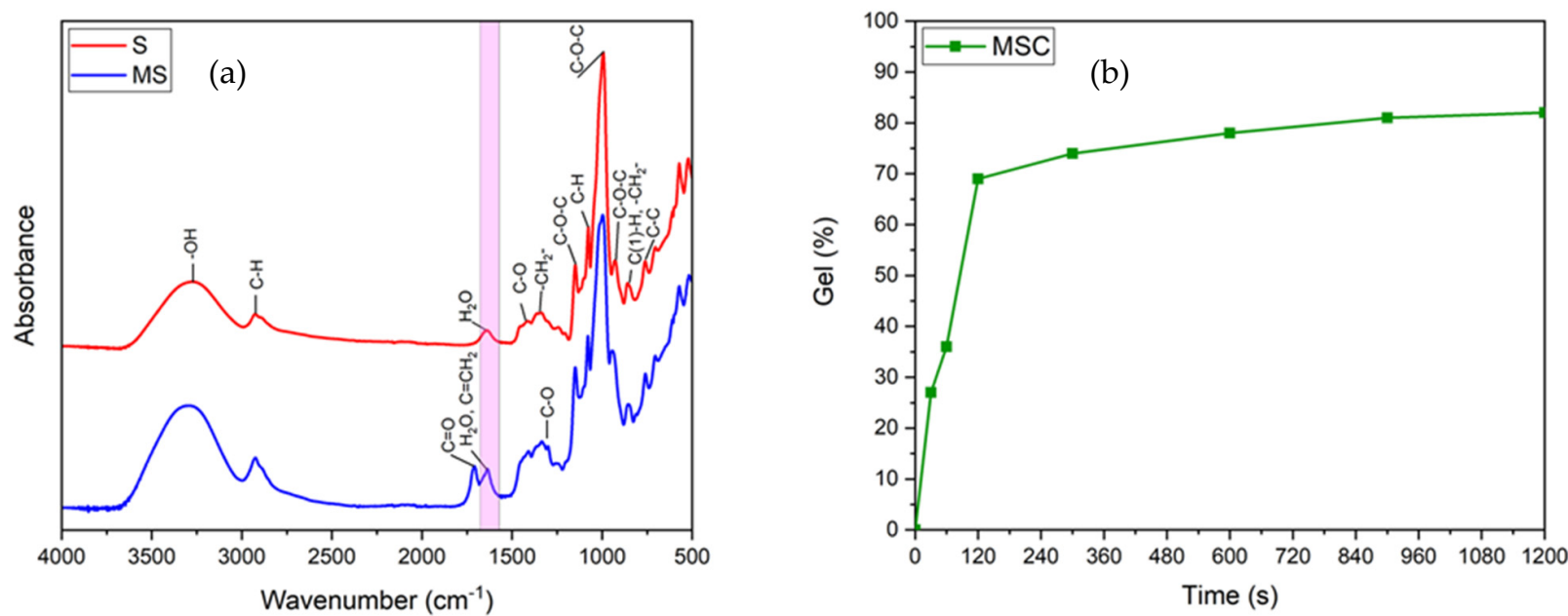

Figure 1. (a) FTIR spectra of Starch (S) and methacrylated starch (MS); (b) Evaluation of gel content after different UV-curing times for MSC films. 


\subsection{Thermal and Mechanical Properties}

Thermal and mechanical properties of both uncured casted films of methacrylated starch (MS) and UV-cured methacrylated starch coatings (MSC) were evaluated in order to show the effect of crosslinking reaction on the final performance of the coatings. The DSC and tensile test are presented in Figure $2 a, b$, respectively, and the properties are summarized in Table 1.
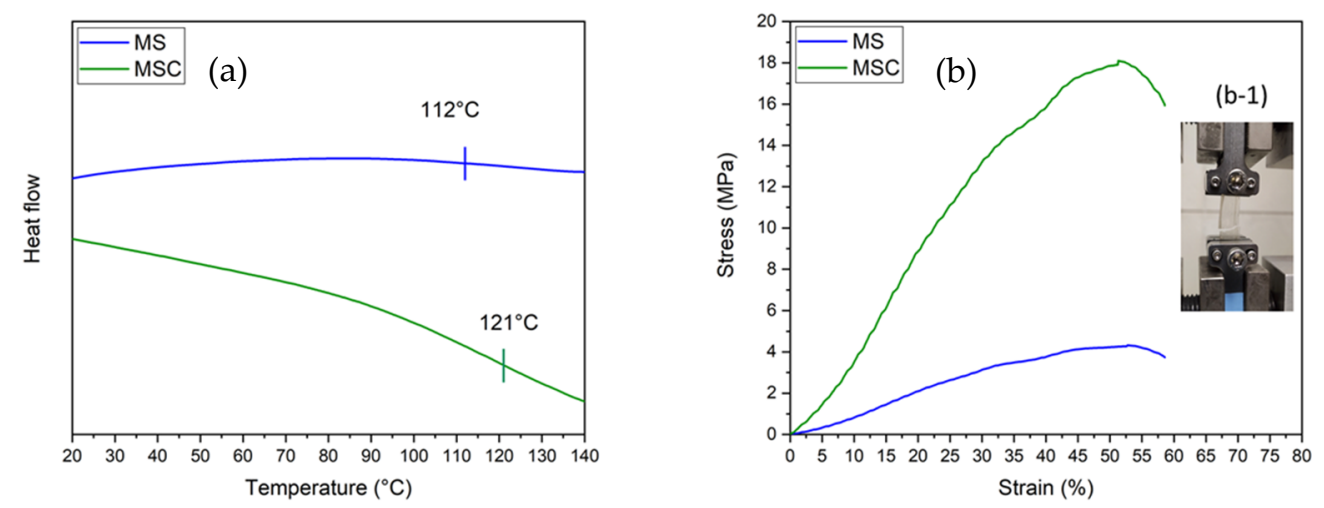

Figure 2. (a) DSC thermogram of MS and MSC; (b) Stress-strain curve of MS and MSC. (b-1) tensile fracture image.

Table 1. Thermal and mechanical properties of the MSC.

\begin{tabular}{ccccc}
\hline Sample & $\mathbf{T}_{\mathbf{g}}\left({ }^{\circ} \mathbf{C}\right)$ & $\begin{array}{c}\text { Young's } \\
\text { Modulus (MPa) }\end{array}$ & $\begin{array}{c}\text { Elongation at } \\
\text { Break (\%) }\end{array}$ & $\begin{array}{c}\text { Ultimate Tensile } \\
\text { Strength (MPa) }\end{array}$ \\
\hline MS & 112 & $9.4 \pm 0.9$ & $49 \pm 12$ & $4.3 \pm 1.2$ \\
MSC & 121 & $39.3 \pm 5.7$ & $48 \pm 15$ & $18.1 \pm 2.9$ \\
\hline
\end{tabular}

In Figure 2a the DSC thermograms are reported respectively for MS and MSC, showing an important enhancement of the glass transition temperature $\left(\mathrm{T}_{\mathrm{g}}\right)$ in the case of the UVcured coatings. This can be attributed to the network formation upon UV-irradiation which hindered the chain mobility with the consequent enhancement of the $T_{g}$ value. Those $T_{g}$ values are similar to the ones obtained in literature for other crosslinked high amylose maize starch systems [46].

The Young's modulus $(E)$ of both MS and MSC was evaluated by the slope of the initial part of the stress-strain curve (Figure 2b). It can be clearly seen that after the irradiation, the mechanical properties of the starch films were enhanced. In fact, for the MSC films the Young's modulus and the ultimate tensile strength are increased by $420 \%$, while the elongation at break remains unchanged. These results can also be ascribed to the cross-linking reaction. These achieved values are comparable with the reported one of gellan/gelatin composite films [47] and higher than those reported for the crosslinked neat cassava and wheat starch with sodium benzoate $[34,36]$. By observing the data reported in Table 1 we can conclude that the crosslinking reaction improves the final performance of the starch-based coatings, and the UV-curing process is quite efficient.

\subsection{Surface Properties of the UV-Cured Coatings}

The UV-cured MSC coatings were visually perfectly transparent (Figure 3a). The surface properties of the MSC UV-cured coating were evaluated by means of pencil hardness, surface adhesion, solvent resistance and surface tension. 
(a)

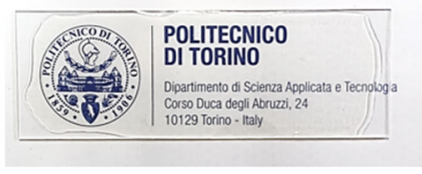

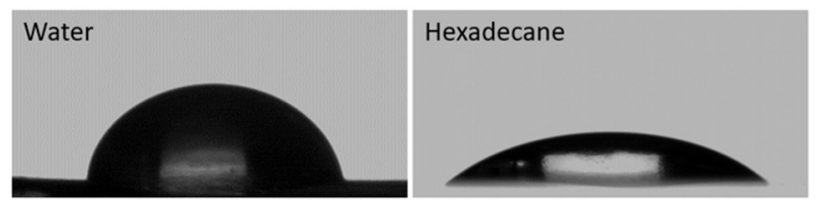

Figure 3. (a) The fully transparent MSC coating on a glass substrate; (b) images of water and hexadecane drops on the surface of MSC.

MSC illustrated high pencil hardness corresponding to 7H (Table 2). This value is higher than the ones reported in literature for other fully biobased coatings $[48,49]$. Since it was previously reported that the pencil hardness depends on the flexibility of the polymeric chains, the high values obtained by MSC can be ascribed to the presence of a large quantity of rigid glucose rings in the starch polymer. Furthermore, the crosslinking reaction may have contributed to enhancing the film hardness [50].

Table 2. Surface properties of the UV-cured MSC coating.

\begin{tabular}{ccccccc}
\hline Sample & Pencil Hardness & Adhesion (\%) & MEK Resistance & $\begin{array}{c}\text { Water Contact } \\
\text { Angle }\left({ }^{\circ}\right)\end{array}$ & $\begin{array}{c}\text { Hexadecane Contact } \\
\text { Angle }\left({ }^{\circ}\right)\end{array}$ & $\gamma(\mathrm{mN} / \mathrm{m})$ \\
\hline MSC & $7 \mathrm{H}$ & 99 & $>200$ & $85 \pm 5$ & $24.8 \pm 4$ & 29.8 \\
\hline
\end{tabular}

The MSC coating adhesion was evaluated with the scratch test following the ASTM D3359-B process. MSC coatings showed excellent surface adhesion on glass (Table 2). Different works have previously investigated the possible adhesion mechanisms. The most common mechanisms are mechanical coupling, molecular bonding, and thermodynamic adhesion. The molecular bonding mechanism is based on intermolecular forces such as dipole-dipole and Van der Waals forces [51]. The very good adhesion of UV-cured MSC coatings on glass substrate could be explained considering the high number of hydroxyl groups present in the starch chains able to form a large number of hydrogen bonding with the substrate.

The chemical resistance of the UV-cured MSC was evaluated by the solvent rub resistance test. This type of test correlates, in a qualitatively way, the resistance of the coating to a specific solvent (MEK) with the curing degree. MEK is a suitable solvent for many polymers, including starch. This method is commonly used in industry where the crosslinking degree of coatings cannot be evaluated by conventional laboratory instruments, such as FTIR. MSC coatings possessed high MEK resistance (Table 2), which could be attributed to a high curing degree. As mentioned before the degree of curing could not be evaluated by FTIR analysis, but both MEK resistance and the high gel content values previously discussed as well as the important enhancement of $T_{g}$ and modulus upon UV-irradiation, support the formation of a tightly crosslinked network.

The MSC water contact angle value was around $85^{\circ}$ (see Figure $3 \mathrm{~b}$ ), which is higher than the values reported in literature for starch-based films [52]. This hydrophobicity enhancement can be ascribed to the crosslinking reaction. The hexadecane contact angle was also evaluated (Figure 3b) to quantitatively characterize the surface energy of the coating $(\gamma)$. The fabricated MSC coating possessed quite a low surface tension value: $29.8 \mathrm{mN} / \mathrm{m}$, calculated using OWRK model (Table 2). The low $\gamma$ value indicates poor wetting capability. This may result in improved antifouling properties [53].

\subsection{Enzymatic Degradation}

In order to assess the effect of curing on the biodegradability, the MS and MSC coatings were subjected to an enzymatic degradation test. The term biodegradation may be defined as "gradual breakdown of a material mediated by a specific biological activity" [54].

In particular, this work evaluated the susceptibility of starch-based coatings to enzymatic degradation by $\alpha$-amylase (from Bacillus licheniformis) enzyme. B. licheniformis is a gram-positive thermophilic bacterium commonly present in soil [55]. The choice of this 
particular enzyme aims to lay the foundations for further composting experiments for the crosslinked coatings.

$\alpha$-amylases are enzymes able to split the $\alpha-1,4$ glycosidic linkage in polysaccharides leading to low-molecular-weight products like glucose, maltose, and maltotriose [56]. For this reason, the starch films degradation was evaluated by quantifying the concentration of glucose and maltose present in the starch-enzyme solution at different time points. The results for the uncured MS film and for the UV-cured MSC are collected in Figure 4a,b, respectively, showing the glucose and maltose formation upon enzymatic degradation. The tested films started to fragment already after 4 days of incubation.

The concentrations of both glucose and maltose were quite similar in the MS and MSC supernatants. Indeed, significant differences $\left({ }^{*} p<0.05\right)$ were observed only for maltose concentration at 7 days, where a higher amount was measured in MSC supernatants. This strongly indicates that the effect of the crosslinking reaction on the enzymatic degradation kinetics of starch-based film was negligible. In Figure $4 \mathrm{~b}$, it is possible to observe a sharp decrease of maltose concentration after 14 days of incubation, while the glucose concentration shows a constant linear increase (with significant differences- $p>0.05-$ among each time point). It thus seems that the $\alpha$-amylase can ultimately degrade maltose to glucose if left to react for a longer period. After 14 days, no solid films remained.

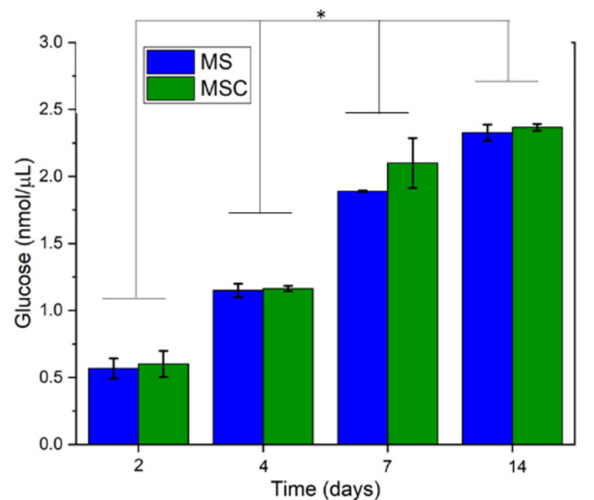

(a)

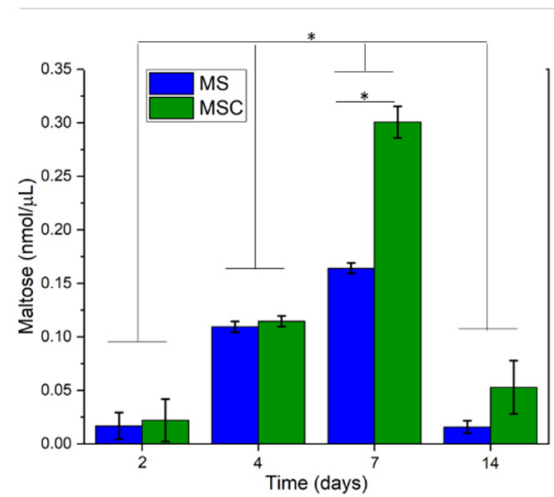

(b)

Figure 4. The amount of (a) glucose and (b) maltose formed during enzymatic degradation of MS and MSC. Significant increase of maltose and glucose was observed at the different time points. The sample MSC did not show any significant difference compared to MS except for values of maltose at 7 days $\left({ }^{*} p<0.05\right)$.

\section{Conclusions}

Starch was successfully methacrylated with methacrylic anhydride and the methacrylate functionalities were exploited during the UV-curing process. The UV-curing resulted in stable starch-based coatings. The efficiency of UV-curing was evaluated by measuring the insoluble content $(\mathrm{Gel} \%)$ after different irradiation time. A plateau corresponding to the formation of an almost insoluble network (79\%) was reached after about 10 min of irradiation. The UV-crosslinking reaction improved the final performance of the starch-based MSC coating, with a $10^{\circ} \mathrm{C}$ enhancement of $\mathrm{T}_{\mathrm{g}}\left(121^{\circ} \mathrm{C}\right)$ and $420 \%$ increase in Young's modulus (39 MPa) and the ultimate tensile strength (18 MPa) with respect to the uncured MS.

The MSC coating possesses high pencil hardness $(7 \mathrm{H})$, excellent adhesion $(99 \%)$, and good solvent MEK resistance ( $>200$ ). The susceptibility of MS and MSC to biodegradation by $\alpha$-amylase (from Bacillus licheniformis) was evaluated and compared. The results show that the degradation velocity was not affected by the crosslinking reaction.

Therefore, we have demonstrated the possibility to exploit methacrylic functionalization of starch to achieve new types of UV-cured coatings. The preliminary enzymatic degradation results are encouraging and will be further implemented by compostability evaluation. 
Author Contributions: Conceptualization and funding acquisition, M.S.; methodology, formal analysis, C.N., C.T.-T., and I.C.; writing-original draft preparation, C.N.; resources, software, and writing-review, editing, supervision and project administration, M.S. and M.H.; All authors have read and agreed to the published version of the manuscript.

Funding: This research received no external funding.

Institutional Review Board Statement: Not applicable.

Informed Consent Statement: Not applicable.

Data Availability Statement: Not applicable.

Conflicts of Interest: The authors declare no conflict of interest.

\section{References}

1. Hassan, B.; Chatha, S.A.S.; Hussain, A.I.; Zia, K.M.; Akhtar, N. Recent advances on polysaccharides, lipids and protein based edible films and coatings: A review. Int. J. Biol. Macromol. 2018, 109, 1095-1107. [CrossRef]

2. Dastpak, A.; Yliniemi, K.; De Oliveira Monteiro, M.C.; Höhn, S.; Virtanen, S.; Lundström, M.; Wilson, B.P. From waste to valuable resource: Lignin as a sustainable anti-corrosion coating. Coatings 2018, 8, 454. [CrossRef]

3. Wang, S.; Ma, S.; Xu, C.; Liu, Y.; Dai, J.; Wang, Z.; Liu, X.; Chen, J.; Shen, X.; Wei, J.; et al. Vanillin-derived high-performance flame retardant epoxy resins: Facile synthesis and properties. Macromolecules 2017, 50, 1892-1901. [CrossRef]

4. Hu, Y.; Tian, Y.; Cheng, J.; Zhang, J. Synthesis of eugenol-based polyols via thiol-ene click reaction and high-performance thermosetting polyurethane therefrom. ACS Sustain. Chem. Eng. 2020, 8, 4158-4166. [CrossRef]

5. Xin, J.; Zhang, P.; Huang, K.; Zhang, J. Study of green epoxy resins derived from renewable cinnamic acid and dipentene: Synthesis, curing and properties. RSC Adv. 2014. [CrossRef]

6. Pezzana, L.; Mousa, M.; Malmström, E.; Johansson, M.; Sangermano, M. Bio-based monomers for UV-curable coatings: Allylation of ferulic acid and investigation of photocured thiol-ene network. Prog. Org. Coat. 2021, 150. [CrossRef]

7. Noè, C.; Hakkarainen, M.; Sangermano, M. Cationic UV-curing of epoxidized biobased resins. Polymers 2021, 13, 89. [CrossRef]

8. Chow, W.S.; Tan, S.G.; Ahmad, Z.; Chia, K.H.; Lau, N.S.; Sudesh, K. Biodegradability of epoxidized soybean oil based thermosets in compost soil environment. J. Polym. Environ. 2014, 22, 140-147. [CrossRef]

9. Auvergne, R.; Caillol, S.; David, G.; Boutevin, B.; Pascault, J.P. Biobased thermosetting epoxy: Present and future. Chem. Rev. 2014, 114, 1082-1115. [CrossRef]

10. Sharmin, E.; Zafar, F.; Akram, D.; Alam, M.; Ahmad, S. Recent advances in vegetable oils based environment friendly coatings: A review. Ind. Crops Prod. 2015, 76, 215-229. [CrossRef]

11. Tan, S.G.; Chow, W.S. Biobased epoxidized vegetable oils and its greener epoxy blends: A review. Polym. Plast. Technol. Eng. 2010, 49, 1581-1590. [CrossRef]

12. Malburet, S.; Mauro, D.; Noè, C.; Mija, A. Sustainable access to fully biobased epoxidized vegetable oil thermoset materials prepared by thermal or UV-cationic processes. RSC Adv. 2020, 41954-41966. [CrossRef]

13. Ma, S.; Li, T.; Liu, X.; Zhu, J. Research progress on bio-based thermosetting resins. Polym. Int. 2016, 65, 164-173. [CrossRef]

14. Lacroix, M.; Le, T.C. Edible films and coatings from non- starch polysaccharides. Innov. Food Packag. Overiew 2005, 338-361. [CrossRef]

15. Alves, V.; Costa, N.; Hilliou, L.; Larotonda, F.; Gonçalves, M.; Sereno, A.; Coelhoso, I. Design of biodegradable composite films for food packaging. Desalination 2006, 199, 331-333. [CrossRef]

16. Biopolymers - New Materials for Sustainable Films and Coatings; Plackett, D. (Ed.) John Wiley \& Sons, Ltd.: Chichester, UK, 2011; Volume 272, ISBN 9781119994312.

17. Ayoub, A.S.; Rizvi, S.S.H. An overview on the technology of cross-linking of starch for nonfood applications. J. Plast. Film Sheeting 2009, 25, 25-45. [CrossRef]

18. Turco, R.; Ortega-Toro, R.; Tesser, R.; Mallardo, S.; Collazo-Bigliardi, S.; Boix, A.C.; Malinconico, M.; Rippa, M.; Di Serio, M.; Santagata, G. Poly (lactic acid)/thermoplastic starch films: Effect of cardoon seed epoxidized oil on their chemicophysical, mechanical, and barrier properties. Coatings 2019, 9, 574. [CrossRef]

19. Martins, Y.A.A.; Ferreira, S.V.; Silva, N.M.; Sandre, M.F.B.; Filho, J.G.O.; Leão, P.V.T.; Leão, K.M.; Nicolau, E.S.; Plácido, G.R.; Egea, M.B.; et al. Edible films of whey and Cassava starch: Physical, thermal, and microstructural characterization. Coatings 2020, 10, 59. [CrossRef]

20. Eddin, A.S.; Tahergorabi, R. Efficacy of sweet potato starch-based coating to improve quality and safety of hen eggs during storage. Coatings 2019, 9, 205. [CrossRef]

21. Escamilla-García, M.; Reyes-Basurto, A.; García-Almendárez, B.E.; Hernández-Hernández, E.; Calderón-Domínguez, G.; RossiMárquez, G.; Regalado-González, C. Modified starch-chitosan edible films: Physicochemical and mechanical characterization. Coatings 2017, 7, 224. [CrossRef]

22. Zhang, Y.; Rempel, C.; Liu, Q. Thermoplastic starch processing and characteristics-A review. Crit. Rev. Food Sci. Nutr. 2014, 54, 1353-1370. [CrossRef] [PubMed] 
23. Kim, M.; Lee, S.J. Characteristics of crosslinked potato starch and starch-filled linear low-density polyethylene films. Carbohydr. Polym. 2002. [CrossRef]

24. Woo, K.; Seib, P.A. Cross-linking of wheat starch and hydroxypropylated wheat starch in alkaline slurry with sodium trimetaphosphate. Carbohydr. Polym. 1997, 33, 263-271. [CrossRef]

25. Woo, K.S.; Seib, P.A. Cross-linked resistant starch: Preparation and properties. Cereal Chem. 2002, 79, 819-825. [CrossRef]

26. Reddy, I.; Seib, P.A. Modified waxy wheat starch compared to modified waxy corn starch. J. Cereal Sci. 2000, 31, 25-39. [CrossRef]

27. Hamdi, G.; Ponchel, G.; Duchêne, D. Formulation of epichlorohydrin cross-linked starch microspheres. J. Microencapsul. 2001, 18, 373-383. [CrossRef]

28. Sangermano, M.; Razza, N.; Crivello, J.V. Cationic UV-curing: Technology and applications. Macromol. Mater. Eng. 2014, 299 , 775-793. [CrossRef]

29. Sangermano, M.; Roppolo, I.; Messori, M. UV-cured functional coatings. RSC Smart Mater. 2015, 2015, $121-133$.

30. Sangermano, M.; Roppolo, I.; Chiappone, A. New horizons in cationic photopolymerization. Polymers 2018, 10, 136. [CrossRef]

31. Hedin, J.; Östlund, Å.; Nydén, M. UV induced cross-linking of starch modified with glycidyl methacrylate. Carbohydr. Polym. 2010, 79, 606-613. [CrossRef]

32. Noè, C.; Tonda-Turo, C.; Chiappone, A.; Sangermano, M.; Hakkarainen, M. Light processable starch hydrogels. Polymers 2020, 12, 1359. [CrossRef] [PubMed]

33. Zhai, M.; Yoshii, F.; Kume, T. Radiation modification of starch-based plastic sheets. Carbohydr. Polym. 2003, 52, 311-317. [CrossRef]

34. Delville, J.; Joly, C.; Dole, P.; Bliard, C. Solid state photocrosslinked starch based films: A new family of homogeneous modified starches. Carbohydr. Polym. 2002, 49, 71-81. [CrossRef]

35. Detduangchan, N.; Wittaya, T. Effect of UV-treatment on properties of biodegradable film from rice starch. World Acad. Sci. Eng. Technol. 2011, 81, 464-469.

36. Zain, A.H.M.; Wahab, M.K.A.; Ismail, H. Solid-state photo-cross-linking of cassava starch: Improvement properties of thermoplastic starch. Polym. Bull. 2018, 75, 3341-3356. [CrossRef]

37. Delville, J.; Joly, C.; Dole, P.; Bliard, C. Influence of photocrosslinking on the retrogradation of wheat starch based films. Carbohydr. Polym. 2003, 53, 373-381. [CrossRef]

38. Zhou, J.; Zhang, J.; Ma, Y.; Tong, J. Surface photo-crosslinking of corn starch sheets. Carbohydr. Polym. 2008, 74, 405-410. [CrossRef]

39. ASTM D3363-05 International Standard Test Method for Film Hardness by Pencil Test 1; ASTM: West Conshohocken, PA, USA, 2005.

40. ASTM D3359-B Standard Test Methods for Measuring Adhesion by Tape Test 1; ASTM: West Conshohocken, PA, USA, 2012.

41. ASTM D5402-06 Standard Practice for Assessing the Solvent Resistance of Organic Coatings Using Solvent Rubs; ASTM: West Conshohocken, PA, USA, 2006.

42. Papadakis, V.G. Estimation of Estimation of surface free energy of polymres. J. Appl. Polym. Sci. 1969, 13, 1741-1747.

43. Kizil, R.; Irudayaraj, J.; Seetharaman, K. Characterization of irradiated starches by using FT-Raman and FTIR spectroscopy. J. Agric. Food Chem. 2002. [CrossRef]

44. Wu, D.; Hakkarainen, M. A closed-loop process from microwave-assisted hydrothermal degradation of starch to utilization of the obtained degradation products as starch plasticizers. ACS Sustain. Chem. Eng. 2014. [CrossRef]

45. Reis, A.V.; Guilherme, M.R.; Moia, T.A.; Mattoso, L.H.C.; Muniz, E.C.; Tambourgi, E.B. Synthesis and characterization of a starch-modified hydrogel as potential carrier for drug delivery system. J. Polym. Sci. Part. A Polym. Chem. 2008. [CrossRef]

46. Liu, X.; Lan, C.; Al, A.; Yu, L.; Zhou, S. Preparation of cross-linked high amylose corn-starch and its effects on self-reinforced starch films. Int. J. Food Eng. 2016, 12, 673-680. [CrossRef]

47. Yeon, K.; Shim, J.; Gyu, H. Mechanical properties of gellan and gelatin composite films. Carbohydr. Polym. 2004, 56, 251-254. [CrossRef]

48. Ma, S.; Kovash, C.S., Jr.; Webster, D.C. Effect of solvents on the curing and properties of fully bio-based thermosets for coatings Effect of solvents on the curing and properties of fully bio-based thermosets for coatings. J. Coat. Technol. Res. 2017. [CrossRef]

49. Nelson, T.J.; Galhenage, T.P.; Webster, D.C. Catalyzed crosslinking of highly functional biobased epoxy resins catalyzed crosslinking of highly functional biobased epoxy resins. J. Coat. Technol. Res. 2013, 10, 589-600. [CrossRef]

50. Gadhave, R.V.; Mahanwar, P.A.; Gadekar, P.T. Effect of glutaraldehyde on thermal and mechanical properties of starch and polyvinyl alcohol blends. Des. Monomers Polym. 2019, 22, 164-170. [CrossRef]

51. Awaja, F.; Gilbert, M.; Kelly, G.; Fox, B.; Pigram, P.J. Adhesion of polymers. Prog. Polym. Sci. 2009, 34, 948-968. [CrossRef]

52. Colivet, J.; Carvalho, R.A. Hydrophilicity and physicochemical properties of chemically modified cassava starch films. Ind. Crops Prod. 2017, 95, 599-607. [CrossRef]

53. Dalvi, V.H.; Rossky, P.J. Molecular origins of fluorocarbon hydrophobicity. Proc. Natl. Acad. Sci. USA 2010, 107, 13603-13607. [CrossRef]

54. Sagnelli, D.; Cavanagh, R.; Xu, J.; Swainson, S.M.E.; Blennow, A.; Duncan, J.; Taresco, V.; Howdle, S. Starch/poly (GlycerolAdipate) nanocomposite film as novel biocompatible materials. Coatings 2019, 9, 482. [CrossRef]

55. Nawaz, M.A.; Pervez, S.; Jamal, M.; Jan, T.; Khan, W.; Rauf, A.; Aman, A.; Qader, S.A.U. Maltose deterioration approach: Catalytic behavior optimization and stability profile of maltase from bacillus licheniformis KIBGE-IB4. Biotechnol. Rep. 2019, 24, e00400. [CrossRef] [PubMed]

56. Rajagopalan, G.; Krishnan, C. $\alpha$-Amylase production from catabolite derepressed bacillus subtilis KCC103 utilizing sugarcane bagasse hydrolysate. Bioresour. Technol. 2008, 99, 3044-3050. [CrossRef] [PubMed] 